\title{
The relationship between College Students' typical psychological problems and physical education*
}

\author{
HongMei WANG
}

Civil Aviation Flight University of China, The Chinese University of Guang Han, SiChuan, China

\begin{abstract}
Today, mental illness is a higher incidence of disease of a kind of spirit, especially to life groups of college students psychological question has its unique features, for the sports teaching can be of some mental illness to positive therapeutic effect.

Keywords -Mental illness, students, physical education

大学生典型心理问题与体育教学关系研究

王红梅

中国民航飞行学院, 广汉, 四川, 中国
\end{abstract}

摘 要 如今, 心理疾病已是发病较高的一种精神疾病, 尤其是以群体生活为主的大学生的心理问题有其独特的特征, 有针对性的体育教 学可以对一些心理疾病起到积极地治疗作用。

关键词 心理疾病, 大学生, 体育教学

1. 引言

根据调查报告显示, 全国各类精神心理障碍症患者, 其 中因工作和学习压力大, 长年亚健康导致超负荷运转的青 年人、大中学生的发病率竟高达 $28.5 \%$ 。我国国情导致现在 的青年人的心理负荷非常大, 需要具备过硬的心理品质, 在 大学生的心理素质培养模式中, 我们必须通过多种手段加 以良性干预。体育教学作为一种专项体育运动, 是在身体练 习的基础上结合某些锻炼器械所进行的一项体育运动, 通 过体育运动使大学生具备良好的身体素质及心理素质, 从 而达到保证提高大学生全面素质水平的提高的工作目的。 因为心理素质在大学生培养过程中的重要性, 逐渐受到各 个招聘公司等的广泛关注。但是, 体育教学在大学生心理素 质培养中所占比例不高, 受重视程度不够, 面临着发展中的 许多问题, 这使得我国大学体育教育水平不但远远落后于 世界平均水平, 而且还使许多大学生全面素质提高计划受 到一定程度的限制。进一步强化体育教学和心理健康教育 的结合既是有效的良性干预手段, 也是全面提高大学生的 综合素质的有效手段, 同时也是培养大学生的高等院校应

*中国民航飞行学院面上项目支持（项目号：J2014-95)
尽的职责。

\section{2. 心理疾病体育调节的实施}

通常来说, 大学生典型的心理疾病分为以下五种类型: 焦虑症、抑郁症、神经衰弱症、各种类型恐惧症以及强迫 症等, 其中焦虑症占所有心理疾病总数的一半, 其次是抑郁 症和神经衰弱症, 就这些心理疾病的性质来看, 都归属于神 经官能症, 是人体系统功能暂时性的失调所导致的, 是功能 性障碍疾病, 这些心理疾病如果通过及时合理的治疗是可 以完全治愈的。在心理疾病的调节与治疗方面, 许多发达的 国家开展比较早, 而我国较迟。其方法通常是采用心理疏 导、暗示、行为治疗等方法, 更多的采用药物治疗, 以追求 见效快的效果。而本文是通过体育教学调节心理的原则是 循序渐进适可而止, 因人而异, 因病而异。如果没有或缺乏 需要、兴趣和动机的指向性, 人就不可能在某一特定范围内 进行或持续进行各种智力因素含量较高的活动。体育教学 是进行体育活动的内在动机之一, 也是表现动机的一种外 在形式, 它具有对未来活动的准备、对正在进行的活动的推 
动作用和对创造活动的促进作用。在教学中, 有兴趣的学生 会目光畑昫、专心致志。在开始接触体育课某技术内容时 都表现出较大的兴趣, 可是在学到有一定难度的技术动作 时, 就会出现兴趣的转移或消失, 这时他们对教师所教授的 内容视而不见、充耳不闻。此刻, 教师就应对教材内容进行 适当的穿插; 对教法进行适当调整; 对男女生的教法要有 区别等, 以重新引起学生的学习兴趣。具体的方法很多, 总 体而言是新颖、独特。体育教师可以通过学生的很多具体 表现观察其兴趣的高低, 据此分析学生的动机水平, 以便及 时进行教学转变, 有效地保持学生在课堂教学中的积极情 绪。教学过程中如果忽视对动机的正确把握, 就会出现事倍 功半的结果。耶基斯・道得逊规律告诉我们: “课题越简单, 学习者需要的动机越高, 课题越复杂, 则要求的动机水平越 低。”体育课的一般教学内容都是从基础教育入手, 技术动 作难度都达不到较高的水平, 因此对动机的需求水平应当 较高。当然, 动机水平的高低也应该适度, 如果过高或过低 都将对教学过程产生消极的影响, 正确地利用动机水平对 于教师来说是一个经验和责任心的问题, 而且对于不同的 项目, 教师对学生动机水平的把握也要有所不同。一般在教 学过程中, 教师可通过先进行新教材的学习, 后进行复习, 将学生的动机水平调动至一个适宜高度, 然后进行各种方 式的技术动作的练习, 使学生能够趣味盎然, 总产生一种跃 跃欲试的相对较高水平的动机, 随后可以调整练习强度, 如 采用运动比赛形式来保障学生较高动机水平的维持, 只有 学生的学习动机始终保持一个比较高且适宜的水平, 才能 有效的完成教学任务。同时, 教师要看到一个阶段某种需要 满足和新的需要较强烈地出现之前, 两者之间还会有一个 “波谷”, 在此阶段学生可能会出现一些较为反常的情绪波 动, 此时教师要及时地以新颖教法引导学生向新的需求方 向发展、过渡。比如可以通过体育比赛或游戏呈现教材的 某些内容, 要求学生在比赛中充分地表现个人或集体的作 用, 教师再及时地加以引导, 使学生正确认识从属、爱、尊 重的需要与将来自我实现及社会价值需要之间的关系, 这 样学生就会逐渐地提高需要层次, 使学习动机持久、适宜。

\section{3. 个性心理特征与体育训练}

根据卡特尔简化理论公式 $R=f(P \bullet S)$, 个人人格及其 情景即是一个人的行为。所以, 体育教师这个与学生在开放
环境中直接接触的职业人物, 必须了解学生人格的重要构 件一一气质类型, 了解和基本掌握学生的气质类型就能较 容易地预测学生的行为方式, 为教学方法提供依据。卡特尔 认为气质决定着一个人对情景作出反应时所表现出的能力 强弱、速度快慢和情绪状态。对此, 学校应该在学生入学时, 做一次气质类型的检测, 为各类教师因材施教提供参考。对 于不具备这种条件的学校, 体育教师可以在课堂教学过程 中逐步地摸索学生的气质类型。荣格认为: “自我是我们能 意识到的一切心理活动, 自我构成了意识域的中心, 负有实 现日常生活机能的责任, 并且具有使我们感到自身同一性 和自身存在的时间连续性的功能。” 自我意识会帮助学生克 服自身存在的问题, 将自己已经转移的兴趣逐步拉回来, 教 师可以利用学生身上所发生的这一变化, 鼓励学生通过各 种能力的提高不断地完善自我。教师在教学过程中可有计 划地给学生自我表现的机会, 为他们实现自我创造融洽的 气氛, 这样做的教学效果十分有效。

全面推进大学生素质教育、培养身心和谐、全面发展 的一代新人。在大学生心理健康教育培养过程中, 体育教学 要承担起实施心理健康教育的重要任务, 一方面大学生的 心理健康教育是现代教育的重要内容, 是社会主义精神文 明的重要基础; 另一方面心理健康教育是促进大学生身心 健康成长的有效途径, 是大学生顺利完成培养目标的重要 保证。基于人的身体健康和心理健康之间存在着紧密的内 在联系, 加强体育对大学生心理健康发展的良性干预作用, 本文从体育的教学心理健康教育功能出发, 探讨体育教学 在实施心理健康教育中的良性干预实践策略, 改变现有的 体育教育状况, 为大学生的身心全面发展服务。

\section{参考文献(References)}

[1] North. T. C MoCulla P \& Tran Z V .Effect of exercise on depression. In K. B PandoIf\& J. O. Holloszy (Eds), Exercise and sport Science Review, 1990. 18, 379-415.

[2] Ledmtaine T P. Aerobic exercise and mood; brief review. 1985-1990. Sports Medicine. 1992, 13 (3). 160-170

[3] Bravdey L R.Motivation Participation in the fitness group. Recreation Research Rewiew. 1979, 6, 35-39 